\title{
GODLINESS IS NEXT TO CLEANLINESS BUT SEX IS SINFUL: THE ROLES OF DISGUST IN RELIGIOUS SCRUPULOSITY
}

\author{
BY \\ Patrick A. Stewart, Thomas G. Adams Jr. \& Carl Senior
}

${ }^{1}$ University of Arkansas, 428 Old Main Fayetteville, AR 7270, USA.

Department of Psychiatry, Yale University School of Medicine, CT 06520, USA

${ }^{3}$ Aston University, Aston Triangle, Birmingham, B47ET, UK.

Correspondence: pastewar@uark.edu 


\begin{abstract}
There is a growing literature suggesting disgust plays a major role in religiosity. However the relationship between different domains of disgust sensitivity and general religious fundamentalism or religious scrupulosity remains unknown. Two studies are reported that examined the relationship between specific types of disgust sensitivity i.e., pathogen, sexual, and moral disgust and specific religious beliefs i.e., fear of sin and fear of God. In the first study it was found that fear of sin and fear of God were significantly related to sexual disgust and pathogen disgust, respectively. In the second study the experimental induction of disgust lead to to greater fear of sin but not the fear of God. These findings suggest that pathogen and sexual disgust sensitivities may serve as effective mechanisms for inflated scrupulosity while state disgust is only related to specific forms of scrupulosity. Taken together the outcomes from both studies converge on a greater understanding of the so called 'Human Behavioural Immune System' model that can account for social behaviour with an evolutionary of adaptive benefit and perhaps more importantly highlights the possible drivers of specific religious behaviour.
\end{abstract}

Key words: Disgust; Scrupulosity; Religion; Sexuality; Human Behavioural Immune System (HBIS) 


\section{INTRODUCTION}

When considering the Judeo-Christian religion there are two major factors that are thought to play a major role in motivating and maintaining religiosity (Weeden, Cohen, \& Kenrick, 2008). The first is in-group solidarity by providing honest signals of group membership and commitment through complex codes of conduct while serving as a barrier to out-groups (Fincher \& Thornhill, 2008; Thornhill \& Fincher, 2014b). The second is reproductive support by providing "low-promiscuity, marriage centered, heterosexual, high-fertility sexual and reproductive strategies" (Weeden et al., 2008). Religious scrupulosity is correlated with conservative or traditional sexual and family attitudes and behaviours and religiosity increases in the presence of perceived mating competition ( $\mathrm{Li}$, Cohen, Weeden, \& Kenrick, 2010; Weeden et al., 2008). In other words, religious scrupulosity may operate to prevent risk taking behaviours that might lead, in some circumstances, to pathogen transmission.

Scrupulosity can also be seen to play a major role in religiosity through enhanced selfmonitoring of thoughts and behaviour. As a result, a religiously scrupulous person is persistently concerned as to whether they have sinned in thought, word, or deed (Abramowitz, D Huppert, Cohen, Tolin, \& Cahill, 2002). Psychometric research has revealed two dimensions of scrupulosity i.e., fear of $\sin$, in which individuals assess the frequency of their doubts and fears concerning their sins and the degree to which this affects their everyday life, and fear of God, in which the consequences of disobeying God are assessed (Olatunji et al., 2007; Olatunji, Abramowitz, Williams, Connolly, \& Lohr, 
2007). Together, these two personality traits play a major role in the foundation of religious beliefs that shape behaviour.

A growing literature has considered the role of disgust on the nature, extent, and expression of religious beliefs (e.g., Ritter, Preston, Salomon \& Relihan-Johnson, 2016). While this literature has focused on disgust sensitivity and general religious fundamentalism (Terrizzi Jr, Shook, \& Ventis, 2012; Terrizzi, Shook, \& Ventis, 2010; J. Tybur, Merriman, Caldwell Hooper, McDonald, \& Navarrete, 2010) or specific forms of religious scrupulosity (Olatunji, 2008; Olatunji, Tolin, Huppert, \& Lohr, 2005), there has been a dearth of research considering the relationship between discrete types of disgust sensitivity or even induced disgust (as in elevated state disgust) and specific forms of religious beliefs. The studies reported here attempt to address this gap and delineate the role of different types of disgust sensitivity and induced disgust on these two types of scrupulosity.

At first pass it may not be immediately clear how disgust can facilitate religiosity yet as is discussed above religion serves as an adaptive response to environmental threats such as infectious disease. The facilitation of specific reproductive strategies that are operationalised within certain religious codes is an example of a behavioural mechanism of this adaptive response. This class of behaviours can also be described within a theoretical model called the Human Behavioural Immune System (HBIS) that describes behaviours that have a role protecting individuals and groups from pathogens and infections by delineating psychological boundaries that separate the in- and out-group members (Schaller \& Murray, 2011; Terrizzi Jr, Shook, \& McDaniel, 2012). There are 
obvious similarities here with religious organizations that define boundaries that are constructed to maintain a socially conservative value system that focuses on "adherence to social norms, in-group cohesion and out-group avoidance." (Terrizzi Jr et al., 2012). Indeed, the HBIS may be seen as operating on individuals through belief and behaviour such as promulgating social organizations such as churches, providing an immune system of sorts to prevent contagion within the church by regulating social behaviour and providing a social barrier from those outside the church. In other words: "(A)lthough religion apparently is for establishing a social marker of group alliance and allegiance, at the most fundamental level, it may be for the avoidance and management of infectious disease" (Fincher \& Thornhill, 2008). In light of the fact that the primary role of disgust is the prevention of illness it remains to be seen whether disgust can drive or motivate religious values and, ultimately, behaviour.

However work also suggests that disgust is more than a singular defense system that protects the body from pathogens (Rozin, Haidt, \& McCauley, 2008). Indeed multiple models for disgust exist (Rozin et al., 2000; Olatunji et al., 2007), one recent evolutionaryadaptive framework for disgust is particularly salient (Tybur, Lieberman, \& Griskevicius, 2009), given its focus on sex and morality, for understanding religiosity (Tybur et al., 2010). Here there are three domains for disgust sensitivity, which are three clusters of situations or contexts in which the basic emotion of disgust operates to facilitate individual, cultural, and evolutionary adaptation to promote survival and reproductive success. This particular model of disgust is comprised of pathogen, sexual, and moral domains of disgust sensitivity (Olatunji et al., 2007; Olatunji et al., 2012; J. Tybur et al., 
2010; J. M. Tybur, Lieberman, \& Griskevicius, 2009; J. M. Tybur, Lieberman, Kurzban, \& DeScioli, 2012).

\subsection{The role of Pathogen Disgust and the fear of God}

Pathogen disgust likely mediates the rejection of out-groups that potentially pose the threat of contamination (Schaller \& Murray, 2011). Thus, religious beliefs concerning purity may be related to negative attitudes towards out-groups including homosexuals (Inbar, Pizarro, lyer, \& Haidt, 2012; Olatunji, 2008; Terrizzi Jr et al., 2012), foreigners, and immigrants (Hodson \& Costello, 2007; Navarrete \& Fessler, 2006), and may stem from concern that these groups may potentially transmit pathogens and disease (J. Tybur et al., 2010). In addition to the direct mediation of attitudes about threatening groups, disgust may operate indirectly through religious beliefs and attitudes (Olatunji, 2008). Core disgust - which is highly akin to pathogen disgust - indirectly influences attitudes towards homosexuals through fear of sin and conservative sexual attitudes (Olatunji et al, 2008). In essence, Christian identification is a marker of in-group conformance with norms of purity (Graham, Haidt, \& Nosek, 2009). This in turn limits the potential for infection by pathogens coming from outsiders. Consistent with this is research suggesting religious diversity increases alongside parasite stress levels (Fincher \& Thornhill, 2008; Thornhill \& Fincher, 2014b). As a result, it is hypothesized that pathogen disgust will predict religious scrupulosity generally and of fear of sin and fear of God specifically.

\subsubsection{Sexual Disgust and the fear of sin}


Within social organizations such as religions, sexual disgust may be emphasized to avoid mating with individuals that may jeopardize reproductive success (J. M. Tybur et al., 2012). Reproductive success is an important function of religions, especially as religions tend to champion high fertility and low promiscuity behaviours (Li et al., 2010; Weeden et al., 2008). According to Tybur and colleagues (2009) religion enhances fertility by setting, monitoring, and enforcing social group norms and values through "avoiding reproductively costly sexual behaviours, narrowing the pool of sexual behaviours and partners to those likely to contribute to the production of healthy viable offspring" (p. 106). At the same time, sexuality specific avoidance due to disgust allows for a range of beneficial social interactions that might have been precluded by pathogen-based disgust (Borg \& de Jong,

2012; J. M. Tybur et al., 2009) while also limiting potentially reproductively costly withingroup behaviour. Due to fear of $\sin$ apparently being chiefly concerned with self-regulation to maintain in-group stability, it is hypothesised that sexual disgust sensitivity will be positively related with increased fear of $\sin$.

\subsubsection{Moral Disgust and the fear of $\sin$}

Moral disgust plays an important role for religious organizations by limiting potentially maladaptive behaviours that disrupt social relationships and their cohesion (Chapman \& Anderson, 2013; Russell \& Giner-Sorolla, 2013; J. M. Tybur et al., 2012). Moral disgust may be seen as most divorced from pathogen avoidance and response, yet utilizes many of the same physiological, psychological, and behavioural responses as pathogen and 
sexual disgust (J. M. Tybur et al., 2012). As a result, it is hypothesised that sensitivity to moral disgust will predict both fear of sin and fear of God.

\subsubsection{Exploratory Analysis of Anxiety, Anger, Sex, and Religious Identification}

Personality traits of anxiety and anger need to be considered in the formation of scrupulosity (Olatunji et al., 2005; Olatunji et al., 2007). Trait anger is important for understanding in-group/out-group divisions through aggressive confrontation, not the avoidance propensity seen with disgust. Research considering the three dimensions of disgust has also shown sex differences in response to pathogen, sexual and moral disgust, with females scoring higher in these scales (Olatunji et al., 2012; J. Tybur et al., 2010; J. M. Tybur et al., 2009). Furthermore, in a study considering political conservatism, when controlling for the sensitivity to the various forms of disgust as noted above, men had significantly higher levels of religious fundamentalism than women (J. Tybur et al., 2010). Finally, to examine the effects of personal religious identification participants were also asked to indicate whether they identified as either Christian or non-Christian.

\section{THE DOMAINS OF DISGUST AND RELIGION}

\subsection{METHODS}

\subsection{Participants}

A total of 545 undergraduate students enrolled in introductory psychology courses at a large southern American university took part in this study. The average age reported by 
participants was $19.52(S D=3.32)$ with a majority female $(60.9 \%)$, Caucasian/white (87.7\%), and belonging to "a Christian religion" (88.4\%).

\subsection{Measures}

Revised Penn Inventory of Scrupulosity [PIOS-R: (Abramowitz et al., 2002; Olatunji et al., 2007)] is a 15-item self-report religious scrupulosity scale that consists of two subscales: the 10-item fear of sin scale that measures fears of having committed a religious sin, and the 5-item fear of God scale that measures fears of punishment from

God. Items for this scale are based upon 5-point scales ranging from 0 ('never') to 4 ('constantly'). Internal consistencies for the two scales were moderate.

Three Domains of Disgust Scale (TDDS; Tybur et al., 2009) is a 21-item self-report scale that measures pathogen, sexual, and moral disgust propensity. Each factor is represented by 7 items that are measured on a zero to 6-point scale, ranging from 'not at all disgusting' to 'extremely disgusting'. The TDDS has strong psychometric properties (Olatunji et al., 2012) and is gender invariant (Tybur et al., 2013). Internal consistencies of the TDDS factors in the current study were moderate (see table 1). 
Table 1: Means, standard deviations, alphas and correlations for measures

\begin{tabular}{|c|c|c|c|c|c|c|c|c|c|c|}
\hline & & $\mathrm{M}$ & SD & $\alpha$ & 2. & 3. & 4. & 5. & 6. & 7. \\
\hline 1. & Fear of sin - Revised & 10.44 & 7.85 & 0.93 & $0.77^{* *}$ & $0.17^{* *}$ & $0.17^{* *}$ & 0.07 & $0.24^{* *}$ & $0.19^{* *}$ \\
\hline 2. & Fear of God - Revised & 6.63 & 4.72 & 0.90 & & $0.23^{* *}$ & $0.13^{* *}$ & $0.09^{*}$ & $0.23^{* *}$ & $0.12^{* *}$ \\
\hline 3. & Pathogen Disgust & 24.74 & 8.93 & 0.86 & & & $0.60^{* *}$ & $0.56^{* *}$ & 0.04 & $0.12^{* *}$ \\
\hline 4. & Sexual Disgust & 22.94 & 10.84 & 0.88 & & & & $0.56^{\star *}$ & $-.17^{* *}$ & $0.11^{* *}$ \\
\hline 5. & Moral Disgust & 25.11 & 9.19 & 0.89 & & & & & -.09 & $0.15^{\star *}$ \\
\hline 6. & Trait Anger (STAXI) & 18.16 & 4.39 & 0.79 & & & & & & $0.14^{*}$ \\
\hline 7. & Trait Anxiety (STAI) & 46.55 & 5.63 & 0.89 & & & & & & \\
\hline
\end{tabular}

${ }^{*} p<.05 ;{ }^{* *} p<.01 ;$

Trait Anger Scale: The Trait Anger Scale [STAXI-T; (C. D. Spielberger, 1999)] is a 10item self-report scale that measures the degree to which an individual experiences and expresses anger in general. The STAXI-T utilizes a 4-point scale ranging from 1 ('almost never') to 4 ('almost always'). The STAXI-T had moderate internal consistency in the present study (Table 1).

Trait Anxiety Scale [STAI-T; (C. Spielberger, Gorsuch, Lushene, Vagg, \& Jacobs, ; C. D. Spielberger, 1999)] is a 20 -item self-report scale that assesses an individual's general level of anxiety over the past 2 weeks. The STAI-T uses a 4-point scale ranging from 1 ('not at all') to 4 ('very much so'). Internal consistency of the STAI-T was moderate in the present sample.

\subsection{Procedure}

All data were collected through an online questionnaire, an approach as reliable as inperson data collection (Coles, Cook, \& Blake, 2007), and were awarded participation 
credit. All participants provided IRB approved informed consent prior to completing the online protocol.

\section{RESULTS}

Bivariate correlations were assessed prior to building multivariate regression models (Table 2) predicting fear of $\sin$ and fear of god. Univariate distributions were reasonably normal, as were bivariate plots. Furthermore, checks for multi-collinearity revealed no major violations in the models.

Table 2: Scrupulosity Linear Regression

\begin{tabular}{lcc}
\hline & \multicolumn{2}{c}{ Full Model } \\
\hline & Fear of Sin & Fear of God \\
\hline Pathogen Disgust & .05 & $.16^{\star *}$ \\
Sexual Disgust & $.30^{* *}$ & .09 \\
Moral Disgust & $-.11^{*}$ & -.07 \\
Trait Anger (STAXI) & $.25^{* *}$ & $.24^{\star *}$ \\
Trait Anxiety (STAI) & $.14^{\star *}$ & .080 \\
Religion & $.15^{\star *}$ & $.31^{* *}$ \\
Gender & $-.19^{* *}$ & $-.11^{*}$ \\
\hline \multicolumn{3}{c}{} \\
\hline F-Test & $15.94^{* *}$ & $20.13^{\star *}$ \\
$R^{2}$ & .17 & .21 \\
Adj. $R^{2}$ & .16 & .20 \\
${ }^{*} p<.05 ;{ }^{* *} p<.01$ & &
\end{tabular}

\subsection{Fear of $\operatorname{Sin}$}

The fear of sin equation is significant and explains nearly $20 \%$ variance. With the exception of pathogen disgust, all parameters are significant at an alpha level of $5 \%$. With the exception of moral disgust, all parameters function in the expected direction. Higher moral disgust was associated with lower levels of fear of sin. When the relative influence 
of the variables is considered, sexual disgust is the most powerful predictor, followed closely by trait anger; higher levels of sexual disgust and trait anger are also associated with greater fear of $\sin$. These variables are followed in power by participant sex, whether the participant identifies as a Christian, and finally, trait anxiety. Males and Christians are more likely to fear sin and higher trait anxiety is related to greater fear of sin.

\subsection{Fear of God}

Analysis of the fear of God shows a significant regression model that explains $16 \%$ of thw variance once model parameters are controlled for. The resulting model shows that whether or not the respondent identifies as a Christian is the most powerful variable with Christians endorsing the greatest fear of God. Trait anger and pathogen disgust sensitivity are significantly and positively related to fear of God as well. Finally, participant gender plays a significant role as males are more likely to fear God once the other variables are controlled for.

\section{DISCUSSION}

Results of the first study provide initial evidence that highlight the relationship between specific types of disgust sensitivity and religious fear. In particular, results suggest a positive relationship between two domains of religious scrupulosity and specific domains of disgust sensitivity with sexual disgust predicting a fear of sin and pathogen disgust predicting a fear of God. In the regression model, moral disgust negatively predicts fear 
of $\sin$. This finding, however, appears to be the result of a suppression effect, as the zeroorder correlation between moral disgust and fear of sin was not significant. Although examined as covariates, trait anger strongly and positively predicted both the fear of $\sin$ and the fear of God, trait anxiety positively predicted fear of $\sin$, and men and Christians endorsed greater fear of sin and fear of God.

The present study advances the understanding of emotional processes in relation to religion in two ways. First, it provides evidence for specific emotional traits correlating with religious scrupulosity. Second, domain-specific relationships were found between disgust sensitivity and religious scrupulosity. The findings here provide preliminary evidence for the disease avoidance role of specific religious doctrine with pathogen disgust having uniquely and positively predicted fear of God whereas sexual disgust predicted fear of $\sin$. In other words, our results suggest that disgust sensitivity toward specific types of infectious material and sexual behaviors is related to greater endorsement towards a specific religious doctrine. It may be that adherence to religious doctrine relating to fear of God increases to better distinguish boundaries separating the in-group from out-groups when disease risk is high to enhance in-group member safety from infection. Alternatively, the relationship may be the result of the mostly Christian sample used, given that Christian participants endorsed greater scrupulosity. This may reflect the fact that many JudeoChristian-based religions tend to emphasize cleanliness in doctrine and rituals.

This first study highlights the possible relationship between sensitivity of different domains of disgust and religion. If such sensitivity to disgust is relevant to the manifestation of 
specific behaviours, as would be accounted for with the HBIS model, then the experience of disgust and not just sensitivity would modulate specific religious activity. The second experiment was therefore carried out to assess whether the relationship between disgust and religious scrupulosity is affected by induced disgust. Here it was hypothesised that the induction of disgust through pathogen-based stimuli will have the effect of increasing fear of God based upon the strong and positive correlation between this component of religious scrupulosity and pathogen disgust sensitivity. While pathogen disgust sensitivity was not significantly correlated with fear of $\sin$ when sexual disgust sensitivity was entered as a covariate in the regression equation there remains a significant correlation between pathogen disgust sensitivity and fear of sin, suggesting a pathogen disgust based stimulus should increase not just fear of God, but also fear of sin.

\section{THE EXPERIENCE OF DISGUST AND RELIGION}

\subsection{Participants}

Two hundred and four individuals entered the experiment's website, with 175 successfully completing the study. Of this number, 162 accurately identified one of the treatment images as a manipulation check, with 94 participants in the control condition and 68 in the treatment condition. The average age of participants was 25 years old $(S D=8.38)$, with the majority of participants female $(79.1 \%)$, and identifying as either Catholic or Protestant (87.7\%). 


\subsection{Procedures}

The entire experimental protocol was delivered online and consisted of the experimental condition in which participants viewed three disgust-inducing images (faeces, vomit, a cold sore) and a control condition in which three neutral images were presented to participants (a chair, a tree, a mushroom). These stimuli were collected from the public domain and were matched for picture attributes e.g., complexity, colour etc. Participants were asked to drag an indicator on a 0-100 point scale with the endpoints 'Not at all' and 'extremely to indicate the degree to which they felt disgusted by each of the experimental stimuli. The procedures were based upon that used by Smith and colleagues, (Smith, Oxley, Hibbing, Alford, \& Hibbing, 2011) with participants viewing each image for ten seconds apiece, with five seconds between each image. To verify participants were complying with the task they were asked to submit a description of one of the images they saw. Participants were also asked to complete the PIOS-R and TDDS items as described above. All possible orders of presentation were randomised throughout.

\section{RESULTS}

There were no between group differences in sex, age, religion, moral disgust, sexual disgust, or pathogen disgust (all $p s>.10$ ). Independent samples t-tests were performed to assess the effect of the image-based disgust induction on subjective disgust ratings. The assumption of homogeneity of variance was violated when tested by the Levene test, $F=59.48, p<.001$, even with this taken into account, there were significant differences, 
$t(160)=11.31, p<.001$, between the treatment $(M=67.09, S D=38.68)$ and control $(M$ $=8.43, S D=21.45)$ conditions. Here the experimental stimuli to be extremely powerful in inducing the experience of disgust with a Cohen's $d$ of 1.88 .

Analysis of the effect of disgust induction on fear of God and fear of sin, suggested no violation of homogeneity of variance for either equation $(F=.31, p=.58$ and $F=.69, p=$ .41 , respectively). The findings, however, were counter-intuitive. Specifically, fear of God, which due to the findings of Study 1 was hypothesized to be increased by pathogen disgust induction, was not significantly different from the control group, $t=1.62, p=.11$, $d=.26$. (disgust group $M=8.96, S D=5.60$; control $M=7.62, S D=4.87$ ). On the other hand, participants in the disgust condition were significantly more likely to agree with statements concerning their fear of $\sin , t=2.67, p<.01, d=.42$ (treatment $M=17.10$, $S D=8.70 ;$ control $M=13.57, S D=7.99$ ).

\section{DISCUSSION}

The finding that the induction of disgust had a significant and effect on the fear of $\sin$, but not the fear of God, is unexpected given the relationship between trait pathogen disgust sensitivity with the latter, but not the former, as revealed in Study 1. However, of the three images used to induce disgust in the second study, the one showing an open sore under the lips of the model could be linked to sexual activity, and may have activated this domain. The lack of a stronger effect on fear of God may be explained by the nature of the threats posed by the images in the disgust treatment condition. Specifically, feces, 
vomit, and open sores are addressed on a regular basis within social groups. Thus the connection with fear of sin may be expected due to that dimension's focus on the selfmonitoring of everyday behaviour.

\section{GENERAL DISCUSSION}

Researchers are increasingly appreciating the role played by disgust in religiosity, especially given the central role religion plays in informing social and political attitudes (Olatunji, 2008; Olatunji et al., 2007; Thornhill \& Fincher, 2014b). This study adds to and elaborates on the role played by disgust sensitivity and its induction on religious scrupulosity at the individual level, finding that not only do different types of disgust sensitivities play a role in specific types of religious scrupulosity, with fear of sin most strongly related to with sexual disgust sensitivity and fear of God with pathogen disgust sensitivity, but also that induced disgust influences both types of religious scrupulosity, albeit at different levels. Perhaps most propitiously, this study found that different types of disgust stimuli might have systematically different impacts on the two dimensions of scrupulosity. Here, it appears that of the visual stimuli relevant for sexual disgust, one,

likely the image of a cold sore, has a greater effect on fear of sin than fear of God. This comports well with the assertions of the Three Domains of Disgust Sensitivity model concerning specific evolutionarily adaptations to not just the rejection of those potentially hosting parasites and pathogens to increase survival, but also enhancing the reproductive fitness of group members through sexual disgust. 
The implications of our findings are that the form of religion espoused likely plays an important role in attracting individuals with higher levels of pathogen and sexual disgust sensitivity. At the same time, emphasis on purity - which directly relates to feelings of disgust and response to potential pathogens (Graham et al., 2009; Haidt, 2012; Horberg, Oveis, Keltner, \& Cohen, 2009)- likely works to reinforce the influence of the role of scrupulosity in the lives of congregants both within and outside the church as pertaining to fear of sin and fear of God, respectively. Better understanding of the role of religious scrupulosity in the lives of believers, especially regular churchgoers, likely means a greater appreciation for the content of religious services, especially sermons where the interpretation of religious texts regarding purity laws takes place.

With regard to the relation between sexual disgust sensitivity and fear of $\sin$, both studies provide preliminary evidence for the disease avoidance role of proscribed behaviour within religions. By regulating behaviours such as sexual practices with potentially high degrees of disease risk with limited reproductive value, societies may have been able to limit the degree to which individuals were exposed to diseases. As an alternative explanation, this result may also be due, at least in part, to the mostly Christian sample used in this study. As many of the prohibited or sinful practices within Judeo-Christianity are sexual in nature, it may also be that sexual practices in general come to be associated with disgust through evaluative or other verbal forms of conditioning (Olatunji, Forsyth, \& Cherian, 2007). This alternative explanation may be even more viable, given that some items on the sexual subscale of the TDDS pose relatively little disease risk. 
Although the current study provides strong evidence for the relation between trait and state disgust and religious scrupulosity, findings should be interpreted with caution due to several limitations. The relatively young age of participants limits the generalizability of both studies. Furthermore, the overwhelming majority of participants in both studies identified as Christian. As such, findings may not generalize to individuals of other religious backgrounds. Similarly, the measure for religious scrupulosity is largely based on a monotheistic perspective. Future studies should include more diverse religious perspectives both in sampling and measurement. While the findings from both correlational and experimental designs underscore the role of disgust both as a trait and an induced state, replication is necessary to more strongly support and accurately delineate relation between disgust and religious scrupulosity.

A final factor to consider in future research derives from the region in which both studies were carried out. Specifically, participants were drawn from a population tending to be raised and currently living in the states comprising the American Deep South. This region is noted for being highly conservative, which according to Thornhill and Fincher (Thornhill \& Fincher, 2014a) has beliefs that may be seen as an "ideological defence against infectious diseases" (p. 6). In other words, participants in both studies, in addition to being exposed to religious and cultural teachings that focus on in-group favouritism and outgroup avoidance, as well as concomitant strategies of favouring tradition while avoiding new ideas and practices, also likely have an accentuated response to pathogenic threat. 
Taken together the findings from both studies inform our understanding of the Human Behavioural Immune model and highlight the means by which this theoretical model can account for idiosyncratic social behaviour within a religious group. From an evolutionary perspective it is clearly beneficial to adopt behaviours that ensure survival long enough to pass genetic material to the next generation. The evolution of a codified social system that facilitates such behaviours would make sense. Here we would we have benefited from a form of group cohesion that would have afforded a degree of environmental protection. Additionally, members of the group would have benefitted from behaviours that would have ultimately ensured protection from parasites. As the survival of individuals within such groups became more evident it would have likely have been relatively straightforward to have attributed such longevity to an outside entity or deity.

\section{REFERENCES}

Abramowitz, J. S., D Huppert, J., Cohen, A. B., Tolin, D. F., \& Cahill, S. P. (2002). Religious obsessions and compulsions in a non-clinical sample: The penn inventory of scrupulosity (PIOS). Behaviour Research and Therapy, 40(7), 825-838.

Borg, C., \& de Jong, P. J. (2012). Feelings of disgust and disgust-induced avoidance weaken following induced sexual arousal in women. PloS One, 7(9), e44111.

Chapman, H. A., \& Anderson, A. K. (2013). Things rank and gross in nature: A review and synthesis of moral disgust. Psychological Bulletin, 139(2), 300-327. doi:10.1037/a0030964; 10.1037/a0030964 
Fincher, C. L., \& Thornhill, R. (2008). Assortative sociality, limited dispersal, infectious disease and the genesis of the global pattern of religion diversity. Proceedings of the Royal Society B: Biological Sciences, 275(1651), 2587-2594.

Graham, J., Haidt, J., \& Nosek, B. A. (2009). Liberals and conservatives rely on different sets of moral foundations. Journal of Personality and Social Psychology, 96(5), 10291046.

Haidt, J. (2012). The righteous mind: Why good people are divided by politics and religion Random House LLC.

Hodson, G., \& Costello, K. (2007). Interpersonal disgust, ideological orientations, and dehumanization as predictors of intergroup attitudes. Psychological Science, 18(8), 691-698.

Horberg, E., Oveis, C., Keltner, D., \& Cohen, A. B. (2009). Disgust and the moralization of purity. Journal of Personality and Social Psychology, 97(6), 963.

Inbar, Y., Pizarro, D., lyer, R., \& Haidt, J. (2012). Disgust sensitivity, political conservatism, and voting. Social Psychological and Personality Science, 3(5), 537544.

Li, Y. J., Cohen, A. B., Weeden, J., \& Kenrick, D. T. (2010). Mating competitors increase religious beliefs. Journal of Experimental Social Psychology, 46(2), 428-431. 
Navarrete, C. D., \& Fessler, D. M. T. (2006). Disease avoidance and ethnocentrism: The effects of disease vulnerability and disgust sensitivity on intergroup attitudes. Evolution and Human Behavior, 27(4), 270-282.

Olatunji, B. O. (2008). Disgust, scrupulosity and conservative attitudes about sex: Evidence for a mediational model of homophobia. Journal of Research in Personality, 42(5), 1364-1369.

Olatunji, B. O., Abramowitz, J. S., Williams, N. L., Connolly, K. M., \& Lohr, J. M. (2007). Scrupulosity and obsessive-compulsive symptoms: Confirmatory factor analysis and validity of the penn inventory of scrupulosity. Journal of Anxiety Disorders, 21(6), 771787.

Olatunji, B. O., Adams, T., Ciesielski, B., David, B., Sarawgi, S., \& Broman-Fulks, J. (2012). The three domains of disgust scale factor structure, psychometric properties, and conceptual limitations. Assessment, 19(2), 205-225.

Olatunji, B. O., Forsyth, J. P., \& Cherian, A. (2007). Evaluative differential conditioning of disgust: A sticky form of relational learning that is resistant to extinction. Journal of Anxiety Disorders, 21(6), 820-834.

Olatunji, B. O., Tolin, D. F., Huppert, J. D., \& Lohr, J. M. (2005). The relation between fearfulness, disgust sensitivity and religious obsessions in a non-clinical sample. Personality and Individual Differences, 38(4), 891-902. 
Olatunji, B. O., Williams, N. L., Tolin, D. F., Abramowitz, J. S., Sawchuk, C. N., Lohr, J. M., \& Elwood, L. S. (2007). The disgust scale: Item analysis, factor structure, and suggestions for refinement. Psychological Assessment, 19(3), 281-297.

Rozin, P., Haidt, J., \& McCauley, C. R. (2008). Disgust.

Russell, P. S., \& Giner-Sorolla, R. (2013). Bodily moral disgust: What it is, how it is different from anger, and why it is an unreasoned emotion. Psychological Bulletin, 139(2), 328-351. doi:10.1037/a0029319; 10.1037/a0029319

Schaller, M., \& Murray, D. R. (2011). Infectious disease and the creation of culture. Advances in Culture and Psychology, 1, 99-151.

Smith, K. B., Oxley, D., Hibbing, M. V., Alford, J. R., \& Hibbing, J. R. (2011). Disgust sensitivity and the neurophysiology of left-right political orientations. PLoS One, 6(10), e25552.

Spielberger, C., Gorsuch, R., Lushene, R., Vagg, P., \& Jacobs, G.A.(1983). Manual for the State-Trait Anxiety Inventory,

Spielberger, C. D. (1999). State-trait anger expression inventory-2 Psychological Assessment Resouces.

Terrizzi Jr, J. A., Shook, N. J., \& Ventis, W. L. (2012). Religious conservatism: An evolutionarily evoked disease-avoidance strategy. Religion, Brain \& Behavior, 2(2), 105-120. 
Terrizzi Jr, J. A., Shook, N. J., \& McDaniel, M. A. (2012). The behavioral immune system and social conservatism: A meta-analysis. Evolution and Human Behavior, 34, 99108.

Terrizzi, J. A., Shook, N. J., \& Ventis, W. L. (2010). Disgust: A predictor of social conservatism and prejudicial attitudes toward homosexuals. Personality and Individual Differences, 49(6), 587-592.

Thornhill, R., \& Fincher, C. L. (2014a). Background and overview of the book. The parasite-stress theory of values and sociality (pp. 1-19) Springer.

Thornhill, R., \& Fincher, C. L. (2014b). Religiosity. The parasite-stress theory of values and sociality (pp. 237-264) Springer.

Tybur, J., Merriman, L., Caldwell Hooper, A., McDonald, M., \& Navarrete, C. (2010). Extending the behavioral immune system to political psychology: Are political conservatism and disgust sensitivity really related. Evolutionary Psychology, 8, 599616.

Tybur, J. M., Lieberman, D., \& Griskevicius, V. (2009). Microbes, mating, and morality: Individual differences in three functional domains of disgust. Journal of Personality and Social Psychology, 97(1), 103-122.

Tybur, J. M., Lieberman, D., Kurzban, R., \& DeScioli, P. (2012). Disgust: Evolved function and structure. Psychological Review, 120(1), 65-84. 
Weeden, J., Cohen, A. B., \& Kenrick, D. T. (2008). Religious attendance as reproductive support. Evolution and Human Behavior, 29(5), 327-334.

Schaller, M. (2011). The behavioural immune system and the psychology of human sociality. Philosophical Transactions of the Royal Society B: Biological Sciences, 366(1583), 3418-3426. 